\title{
Origen y contenido mínimo del Derecho constitucional financiero
}

\author{
Eddy De la Guerra Zúñiga*
}

\section{RESUMEN}

El deber de contribución al gasto público es el principal objeto de estudio del Derecho constitucional financiero; si bien el referido deber está originalmente dirigido al legislador, quien por mandato constitucional tiene la obligación de buscar riqueza y allí donde la encuentre establecer tributos a través de la ley, este deber tiene como destinatario final a los ciudadanos, quienes en su condición de "contribuyentes" están obligados a pagar los tributos establecidos en la ley. Esta relación entre ciudadanos y Estado se desarrolla en el marco de un conjunto de principios que rige la contribución al gasto público a través del cual nace y se configura un conjunto de derechos del contribuyente.

En ese sentido, el Derecho constitucional financiero es la rama jurídica que regula las relaciones de deberes y derechos entre el Estado y los contribuyentes, rama jurídica compleja tanto desde la concepción teórica como del espectro regulatorio, pues no existe consenso sobre el nivel de relación con otras ramas como el Derecho administrativo. Este artículo pretende aclarar su filiación epistemológica, aclarar el tipo y nivel de relación con otras ramas del Derecho público, y estudiar brevemente su ámbito de acción.

Palabras Clave: Derecho constitucional financiero, Constitución financiera, deber de contribución al gasto público.

\section{ABSTRACT}

The duty of contribution to public expenditure is the main object of study of the Constitutional Financial Law. Although the referred duty corresponds originally to the legislator, who is the one obligated by the constitutional mandate to seek wealth and wherever it finds it establishes taxes through the law, this duty has as a final destination the citizens, who in their condition of "taxpayers" are obliged to pay all the taxes established in the law. This relationship between citizens and the State is developed through the bond of a set of principles governing the contribution to public expenditure through which a set of taxpayer rights are born and configured.

* Docente e investigadora del Área de Derecho de la Universidad Andina Simón Bolívar, Sede Ecuador. 
In that sense, constitutional law is the legal branch that regulates the relationship of duties and rights between the State and taxpayers, a complex legal branch even from the theoretical conception, as well as regulatory environment, since there is no consensus about the level of relationship with other branches such as Administrative Law. This article aims to clarify its epistemological affiliation, clarify the type and level of relationship with other branches of public law, and briefly study its field of action.

KEYWORDS: Constitutional Financial Law, financial constitution, duty of contribution to public expenditure.

\section{INTRODUCCIÓN}

$\mathrm{E}$ 1 título de este artículo da cuenta de la existencia de una rama del Derecho, por el momento diremos "público"; cuyo estudio e investigación ha tenido muy poco desarrollo, en primer lugar, debido a que no existe claridad respecto a si se trata de una rama del Derecho constitucional o si se trata de una especificidad del Derecho Financiero Público. En ese sentido, este trabajo pretende estudiar esta rama jurídica desde sus raíces para desentrañar su filiación a una rama determinada para luego analizar y estudiar su contenido mínimo.

Merece la pena señalar que la doctrina hoy presentada contiene apenas un extracto de una larga investigación sobre el deber de contribución al gasto público y los principios que le rigen, ${ }^{1}$ que concluyó con el desarrollo de un catálogo de derechos del contribuyente; investigación que no podía llevarse a cabo, sin tener previamente claro el marco teórico que cobija el estudio de los deberes y derechos de los ciudadanos en cuanto a la relación jurídica del gasto público y el vínculo jurídico impositivo, y dicho marco es precisamente el Derecho constitucional financiero.

1. Eddy De la Guerra, El deber de contribución al gasto público y los principios que le rigen (Madrid: Universidad Complutense de Madrid, programa de Doctorado en Derecho, 2016); y, El deber de contribución al gasto público. Principios que lo informan y derechos del contribuyente (México D. F.: Porrúa, 2018). 


\section{FILIACIÓN EPISTEMOLÓGICA DEL DERECHO CONSTITUCIONAL FINANCIERO}

La doctrina ha discurrido considerablemente sobre la naturaleza del Derecho financiero y su relación con el Derecho constitucional, por una parte, y con el Derecho administrativo, por otra; al respecto se han presentado dos posiciones diametralmente opuestas entre sí; la primera resalta una autonomía absoluta del Derecho financiero ${ }^{2}$ frente al Derecho administrativo, al punto de considerarlo únicamente como parte del Derecho público interno, separándolo científica y didácticamente de otras ramas jurídicas; alineados a esa posición encontramos a autores como Vicente-Arche ${ }^{3}$ y Sainz de Bujanda ${ }^{4}$ y Rodríguez Bereijo. ${ }^{5}$ En la segunda postura se encuentran aquellos tratadistas que consideran a este como una parte especial del Derecho administrativo, que a su vez es Derecho público, por ende carente de autonomía, particularmente la científica; autores como Ferreiro Lapatza ${ }^{6}$ se manifiestan alineados a esta posición.

Una tendencia al parecer intermedia es la de Giannini, quien señaló que:

el Derecho financiero forma parte... del Derecho público interno, y más concretamente del Derecho constitucional, en cuanto corresponde al poder legislativo no solo fijar las normas para el desarrollo de la actividad financiera, sino también autorizar anualmente al poder ejecutivo, mediante la aprobación del Presupuesto, para que recaude los ingresos y realice los gastos; dentro de límites prestablecidos. ${ }^{7}$

Y por otro lado "del Derecho administrativo, puesto que [...] el desarrollo concreto de la actividad financiera constituye uno de los cometidos de la Administración Pública". ${ }^{8}$

Giannini, por una parte, afirma inicialmente que el Derecho financiero forma parte tanto del Derecho constitucional como del Derecho administrativo; posteriormente,

2. Rubén Asorey, Andrea Amatucci y Mauricio Plazas Vega, La autonomía del Derecho de la hacienda pública y el Derecho tributario (Bogotá: Universidad del Rosario, 2008).

3. Vicente Domingo Arche-Domingo, "Hacienda pública y administración pública", Hacienda Pública Española, No. 26 (1974).

4. Fernando Sainz de Bujanda, Sistema de Derecho financiero, I, Introducción. Actividad financiera, ciencia financiera, y Derecho financiero, vol. 1 (Madrid: Universidad Complutense de Madrid, 1977), 466-73.

5. Álvaro Rodríguez Bereijo, Introducción al estudio del Derecho financiero (Madrid: Instituto de Estudios Fiscales, 1976), 212-44.

6. José Juan Ferreiro Lapatza, Curso de Derecho financiero español, 14a. ed. (Madrid: Marcial Pons, 1992), 32 y s.

7. Achile Donato Giannini, Instituciones de Derecho tributario, Serie Manuali Giuffrè de Dott Giuffrè Editore, Traducción y estudio preliminar de Fernando Sainz de Bujanda (Madrid, Editorial de Derecho Financiero, 1957 ), 5. Del mismo autor se puede consultar en su versión original en italiano: I concett fundamenttali di diritto tributario (Turín: Utel, 1956).

8. Ibíd. 
en un complejo juego de ordenación de palabras, afirma que aquel se descompone en varias partes ${ }^{9}$ cada una de las cuales con un carácter jurídico propio, unas derivadas del Derecho constitucional y otras atinentes a las relaciones administrativas y, por ende, parte del Derecho administrativo; consecuentemente cabía no hasta hace mucho preguntarse si se trata de un Derecho autónomo que se descompone en varias partes o si se trataba de un Derecho derivado de otro.

Ahora bien, sin lugar a duda el Derecho financiero es Derecho público y su objeto de estudio goza de unidad suficiente para reconocer en nuestros días su completa autonomía científica; en parte por tener como objeto de estudio a la Hacienda configurada como un "todo" plenamente diferenciado del resto de la Administración Pública, y en parte por la particularidad de la actividad financiera que evidencia indiscutiblemente la relación ingreso-gasto que a su vez genera vínculos jurídicos especiales tanto entre sujetos pasivos y Hacienda (ingresos), como entre Estado y pueblo (gastos); en esa dinámica se revela el vínculo o relación de dependencia para con otras ramas del Derecho público.

No cabe duda, en razón de la autonomía científica del Derecho financiero, que se trata efectivamente de un ordenamiento jurídico con unidad; Jaime Guasp,$^{10}$ seguido por Sainz de Bujanda, se refirió a este como un conjunto jurídico significativo que goza de principios propios; ello implica que su objeto, es decir el fenómeno financiero, se diferencia claramente de las demás actividades de administración del Estado, lo que a su vez ha permitido el desarrollo de algunas de sus ramificaciones como el Derecho tributario, presupuestario y patrimonial.

Entonces, si el objeto de la actividad financiera estatal es tanto la administración y gestión de recursos como la ejecución del gasto, entiéndase que se ha de partir de principios y preceptos constitucionales financieros, lo cual demuestra sólidos vínculos con estas dos ramas también del Derecho público, sin que dicha conexión anule la bien consabida autonomía.

Retomando el criterio de Giannini, el autor sostiene que el Derecho financiero se descompone, por tanto, en varias partes, cada una de las cuales tiene un carácter jurídico propio; a saber, la institución presupuestaria, gestión financiera que deriva del Derecho constitucional; y la gestión del patrimonio estatal en lo que comprende al Derecho administrativo; ${ }^{11}$ esta diversificación jurídico-dogmática es precisamente

9. Giannini, Instituciones de Derecho Tributario, 6.

10. Para el autor la idea del Derecho, "más que como un conjunto de normas", debe entenderse "como un conjunto de realidades normadas". Ver Jaime Guasp citado textualmente por Sainz de Bujanda, 320-1.

11. Ver Giannini, Instituciones de Derecho Tributario, 6. 
la causa que evidencia la necesidad de determinación respecto al campo disciplinario fuente del marco teórico que constreñirá la discusión de la tesis propuesta.

En ese sentido, el estudio se ha de inclinar hacia el Derecho constitucional financiero, al que se aspira delimitar en razón de su contenido mínimo y los principios que lo integran; cabe entonces aclarar que no se trata en ningún caso de conferirle autonomía o independencia escindiéndolo de otras ramificaciones del Derecho financiero, se trata únicamente de una necesaria delimitación del enfoque teórico.

Es evidente que en un Estado o bien de Derecho, como lo es España, o bien Constitucional como lo es Ecuador, más allá de las particularidades de cada uno, para ambos la Constitución es la norma jurídica suprema depositaria tanto de los derechos como de las obligaciones de las personas y del propio Estado; dentro de dicha norma fundamental en calidad de obligación se configura en España el deber de contribuir a solventar el gasto público en la medida de la capacidad económica; ${ }^{12} \mathrm{y}$ en Ecuador el deber de pagar los tributos establecidos en la ley.

12. Partiendo del hecho fundamental de que el gasto público se emplea para satisfacer las necesidades identificadas por el poder público, ratificadas en el propio texto constitucional, es preciso señalar que el nexo causal entre la satisfacción de necesidades a través del gasto público y el deber de contribuir se localiza en los 'derechos' constitucionales.

Cada Constitución aglutina las necesidades comunes que se consideran como tal y son responsabilidad del Estado dependiendo del tipo de gobierno y el modelo constitucional vigente; así, en un Estado liberal clásico la política financiera se orientará a satisfacer únicamente las necesidades básicas y fundamentales, dejando que la producción, el mercado y la economía interna produzcan por sí mismos fuentes de satisfacción de las demás necesidades; mientras que un Estado social, a base de las premisas del bien común y del principio de solidaridad, buscará satisfacer la mayor cantidad de necesidades del colectivo en equidad, buscando la redistribución de la riqueza, para lo cual deberá recaudar más y mejor a través del efectivo cumplimiento del deber de contribuir.

Queda claro entonces que, dependiendo del modelo de Estado adoptado, cada uno ha de identificar las necesidades colectivas, les ha de dar un orden de prelación e importancia en razón de la urgencia y ha de buscar los mecanismos para su satisfacción, para lo cual, en primer lugar, configura "derechos" reconocidos en la Constitución, crea mecanismos que garanticen su cumplimiento, al mismo tiempo a manera de compensación por el gasto e inversión efectuado en la satisfacción de tales necesidades establece un conjunto de obligaciones a los beneficiados en calidad de "deberes" constitucionales.

Entiéndase el deber constitucional como aquella conducta instituida por mandato del constituyente cuyo cumplimiento puede ser exigido por ley. Para efectos puntuales en lo relativo a la actividad financiera del Estado, estos deberes públicos se configuran como prestaciones pecuniarias que se imponen tanto a personas naturales como jurídicas, cuya recaudación permite la satisfacción de necesidades, actividad que constituye el fin último del Estado cualquiera sea su forma de organización, - ¿qué tipo de necesidades? y el nivel de prioridades entre ellas es algo que le compete definir a los poderes públicos-, en la que destaca de manera importante la relación que existe entre el ingreso tributario y el gasto público a partir del instituto financiero denominado "deber de contribuir", el sistema que lo instrumenta y los principios que lo informan.

De tal forma que al mismo tiempo en que un ciudadano tiene derechos de diversa naturaleza, también tiene obligaciones (igualmente de diversa naturaleza). Todo ello implica que la Constitución no es la norma jerárquicamente superior simplemente por ser la que regula la vida, estructura orgánica y administración del Estado, sino porque de ella dependen no solo la identificación de necesidades, la determinación de derechos, la configuración de deberes y por ende el establecimiento de garantías que aseguren que tanto derechos como deberes se cumplan 
El referido deber se convierte en el prisma de la actividad financiera del Estado que concierne en forma general al Derecho público, se configura en la norma constitucional, se materializa a través de mecanismos de Derecho administrativo, concierne su regulación y estudio al Derecho tributario en cuanto al vínculo jurídico impositivo entre obligados y Estado se refiere, así como a los diversos hechos generadores y tributos contemplados en la ley; finalmente su producto se destina al gasto público y la distribución de lo recaudado atañe a la materia presupuestaria; todo lo cual concierne al Derecho financiero.

\section{DEFINICIÓN Y ALCANCE}

Más de un centenar de años lleva la discusión jurídica iniciada por el tratadista austriaco Franz von Myrbach-Rheinfeld ${ }^{13}$ en 1906 y que fue retomada décadas más tarde por Sainz de Bujanda; ${ }^{14}$ hoy hemos de remitimos a su doctrina, en compañía de Vogel, ${ }^{15}$ con el objeto de delimitar el campo de estudio.

Sainz de Bujanda manifestó que "efectivamente [...] no todo el Derecho financiero es Derecho administrativo, ya que un importante núcleo de instituciones financieras quedan encuadradas en lo que se denomina [...] - con escaso acierto- Derecho constitucional". ${ }^{16} \mathrm{Tal}$ desacierto lo atribuye precisamente a Myrbach-Rheinfeld, quien, en el inicio del siglo XX afirmó que el Derecho Financiero se construye "por aquellas partes del Derecho público positivo que tienen por objeto la ordenación de la Hacienda de las colectividades públicas (es decir, del Estado y de los cuerpos administrativos autónomos que existen en su interior)"; afirmó, además, que abarca normas de Derecho constitucional y normas de Derecho administrativo; dentro de las primeras, evidentemente se refiere a normas de carácter fundamental y, en las segundas, a leyes ordinarias y reglamentos, de ahí que existan dos concepciones del Derecho financiero. ${ }^{17}$

en equidad; sino además que el deber del contribuir al gasto público ha de cumplirse en la medida de la capacidad económica del contribuyente para lo cual se configuran principios y garantías constitucionales de los cuales se hablará más adelante.

13. Ver Franz von Myrbach-Rheinfeld, Précis de Droit Financier (Leipzing: Verlag von Duncker \& Humblot, 1906). Versión francesa: Précis de Droit Financier (París: V. Giard \& E. Briere, 1910).

14. Ver Sainz de Bujanda, Sistema de Derecho financiero...

15. Ver Klaus Vogel, "Grundzüge des Finanzrechts des Grundgesetzes", en Der offene Finanz- und Steuerstaat (Heidelberg: C. F. Müller, 1991); y “La Hacienda pública y el Derecho Constitucional”, Hacienda Pública Española, No. 69 (Madrid: Ministerio de Economía y Hacienda-IEF, 1979).

16. Ver Sainz de Bujanda, Sistema de Derecho financiero..., 438.

17. Myrbach-Rheinfeld articuló contenidos tanto para el Derecho constitucional financiero como para el Derecho administrativo financiero; así, el primero contiene: 1. El modo de establecer le presupuesto, 2. La aprobación anual de los tributos, 3. El control de la gestión financiera, 4. La emisión y la conversión de los empréstitos, así como la enajenación de los bienes inmuebles y la constitución de cargas sobre los mismos, y, 5. La competencia de las 
Si bien es posible remitirse al criterio de Myrbach-Rheinfeld a través de la interpretación que Sainz de Bujanda hizo en su tiempo a la obra Précis de Droit Financier, es importante aclarar que la intención original del autor fue la de integrarse al estudio sistemático y ordenado de la ciencia jurídico-financiera, que hasta aquel entonces había sido abordada por el Derecho administrativo; su obra es entonces producto de un criterio pluralista por el que el Derecho financiero abarca normas tanto de Derecho constitucional como de Derecho administrativo.

Rescatamos la posición del austriaco, aunque con prudencia, no solo por la influencia que la doctrina germana ha tenido tanto en España como en Ecuador, sino porque además, tal como Sainz de Bujanda afirmó, esta obra está imbuida del núcleo de ideas dominantes en torno a la personalidad del Estado, a la ilimitada extensión de su poder y al mecanismo de la autolimitación de este último, por medio de normas jurídicas, que sirvió a los grandes creadores del Derecho público contemporáneo a construir los cimientos del llamado Estado de Derecho, ${ }^{18}$ que es precisamente la forma estatal en la se configura el deber de contribución al gasto público tal como lo conocemos en la actualidad, más allá de cualquier desliz del autor, en la atribución de algunos contenidos a determinados ámbitos.

Acertadamente señaló el profesor español que algunos de los contenidos de estas dos diversificaciones del Derecho financiero (constitucional y administrativo) son innegablemente cuestionables; no puede olvidarse que la acogida de su criterio sobre la distinción entre un Derecho constitucional financiero y un Derecho administrativo financiero permitió en su tiempo que temas como presupuesto y deuda pública tengan su propio espacio académico dentro del marco del Derecho público; mientras que los temas atinentes a la imposición se estudiaron dentro del marco del Derecho tributario, lo cual incidiría significativamente en la discusión sobre la autonomía académica del Derecho financiero, aunque tendría poca cabida en cuanto al estudio de la autonomía científica, previamente aludida.

En este punto vale la pena aclarar que esta posición influenció notablemente la investigación en Ecuador: los temas impositivos se han venido estudiando en forma no solo autónoma, sino completamente independiente y alejada de los demás contenidos del Derecho financiero, a tal punto que en las últimas cuatro décadas no se ha

Cámaras en cuanto se refiere a la elaboración de las leyes financieras; mientras que al Derecho administrativo le compete: 1. La organización, clasificación, funciones; y competencia de los órganos, 2. Las normas jurídicomateriales mediante las cuales se imponen deberes jurídico-financieros a los particulares, 3. Las prescripciones que han de observarse en la aplicación de las antedichas leyes y los recursos contenciosos establecidos en favor de los particulares; y 4. Las prescripciones referentes al servicio de caja, a la contabilidad, al control interior y a la administración de la deuda. Franz von Myrbach-Rheinfeld, 16-7.

18. Ver Sainz de Bujanda, Sistema de Derecho financiero..., 438. 
conocido ningún estudio relevante que destaque en Ecuador la innegable e importante relación entre los tributos y el gasto público.

Sin embargo de la advertencia que hiciere Sainz de Bujanda sobre sus cuestionamientos a algunos de los contenidos atribuidos por Myrbach-Rheinfeld al Derecho constitucional financiero, el autor no se manifiesta contrario a tal diferenciación en la medida en que no se propenda a una bifurcación del Derecho financiero en dos ramas, nada alega en contra de que se resalten los 'aspectos constitucionales' del Derecho financiero; "antes al contrario, la dimensión jurídico-constitucional de la Hacienda constituyen un ingrediente básico de este sector del ordenamiento, pero no debe servir para escindirlo internamente en dos parte o bloques de instituciones", ${ }^{19}$ las que, ratifica, podrían estar o no constitucionalizadas sin que por ello se altere su sustancia, no así la jerarquía, y en consecuencia la fuerza y rigidez de las normas que las regulen.

Ahora bien, la creciente tendencia neoconstitucionalista y sus corrientes de pensamiento garantista en Suramérica permiten de alguna forma, si bien no reinterpretar, al menos aprovechar aquel criterio de Myrbach-Rheinfeld que para Sainz de Bujanda fuere estrictamente didáctico, para rescatar algunas de sus ideas primarias y denotar de esta forma la constitucionalidad del Derecho financiero; autores como Zagrebels$\mathrm{ky}^{20}$ y Ferrajoli ${ }^{21}$ disertan en la actualidad sobre los principios constitucionales describiéndolos como normas generales y abiertas que regulan derechos y deberes que requieren instrumentación a través de reglas de derecho en calidad de normas infraconstitucionales para ser eficaces.

En ese sentido y para fines estrictamente didácticos se puede describir al Derecho constitucional financiero como aquel que contiene los principios constitucionales que regulan deberes y derechos en el marco del presupuesto, ingresos públicos, sistema impositivo, crédito y deuda pública; mientras que el Derecho administrativo financiero será aquel que instrumentará a través de códigos, leyes, reglamentos y demás normas infra-constitucionales tales principios.

Si bien se podría hacer referencia indistintamente al Derecho constitucional financiero o al Derecho financiero constitucional, para efectos del análisis propuesto cabe aportar una pequeña distinción de orden asimismo estrictamente didáctica; por cuanto "la dimensión jurídico-constitucional de la Hacienda constituye un ingrediente básico de este sector del ordenamiento"22 y considerando que ninguna rama del Derecho

19. Sainz de Bujanda, Sistema de Derecho financiero..., 442.

20. Ver Gustavo Zagrebelsky, El Derecho dúctil (Madrid: Trotta, 2005).

21. Ver Luigi Ferrajoli, Derechos y garantías (Madrid: Trotta, 1999); y, Los fundamentos de los derechos fundamentales (Madrid: Trotta, 2009).

22. Sainz de Bujanda, Sistema de Derecho financiero..., 442. 
puede estudiarse en forma aislada del marco jurídico constitucional y mucho menos la actividad financiera del Estado por la naturaleza de sus contenidos, al menos para efectos de la presente obra, entiéndase que al mencionar al Derecho constitucional financiero se estará haciendo referencia a los principios financieros contenidos en la Constitución; mientras que el Derecho financiero constitucional se referirá a la constitucionalidad y a la eficacia de las normas infraconstitucionales que instrumentan y materializan los principios contenidos en la norma fundamental.

En cuanto al alcance del Derecho constitucional financiero, será la Constitución de cada Estado la norma que determine cuál es su contenido mínimo; en forma general, se ha de referir al presupuesto, ingresos públicos tanto tributarios como no tributarios, gasto público, crédito y deuda pública. El deber de contribución al gasto público, siendo una institución del Derecho financiero que nace conforme lo estipulado en una norma constitucional, ha de cumplirse a través de un sistema tributario justo en la medida de la capacidad económica, es decir que existen derechos y garantías asociados a tal deber, inspirados en aquel conjunto de principios fundamentales.

Con lo dicho queda justificada la línea de investigación asumida y ella es el Derecho constitucional financiero, lo cual implica además que en cuanto al contenido normativo objeto de análisis y la jurisprudencia seleccionada para el estudio se hará especial énfasis en los principios puntuales de la llamada Constitución financiera de ambos estados.

Tal como Sainz de Bujanda afirma, existe sin duda en nuestro tiempo un Derecho constitucional financiero o, si se prefiere, unos principios constitucionales financieros, de carácter más general, que afecta al sistema de producción de normas en la órbita financiera y a la capacidad económica de los ciudadanos como causa y medida de la tributación. ${ }^{23}$

23. Ver Sainz de Bujanda, Hacienda y Derecho, 1955, cita tomada de la reimpresión utilizada en 1962 del Instituto de Estudios Políticos de Madrid, 429. Referido por Perfecto Yebra Martul-Ortega en Constitución Financiera 25 años (Madrid: Ministerio de Hacienda, Instituto de Estudios Fiscales, 2004), 31. Sorprende -al menos a lectores foráneos como en mi caso- en relación a esta afirmación que data de 1955 cuando se encontraban vigentes las Leyes Fundamentales predecesoras a la Constitución vigente, que el mismo autor en 1977 en el volumen I de su obra Sistema de Derecho Financiero, un año antes de la aprobación de la Constitución vigente no ratificara su criterio ni lo complementara; por el contrario, dedicó gran parte de su obra a desagregar los elementos que considera criticables de la teoría de Myrbach-Rheinfeld y el contenido que dicho autor propusiere para el Derecho constitucional financiero décadas atrás, lo que además resulta curioso es que al publicar el volumen II de la misma obra en 1985 es decir, con 7 años de vigencia de la Constitución, tampoco retomare el tema y ni aun en forma introductoria y vaya directamente a justificar la clasificación del Derecho financiero en sus ramificaciones, obra que espléndidamente se desarrolla conforme un análisis desde del Derecho público con sectores proyectados sobre la materia financiera, que no es otra cosa que analizar los contenidos de ramas que convergen en un conjunto tanto de principios constitucionales como de reglas contenidas en la propia Constitución y dicho argumento es válido para todas las Constituciones y no solo para las que son objeto de análisis en el presente estudio. 
Vogel no solo reconoce la existencia de un Derecho constitucional financiero, sino que además aporta una definición y sostiene que se trata de:

aquellos preceptos del Derecho financiero que pertenecen formalmente al Derecho constitucional, o dicho de otro modo, aquellos preceptos del Derecho constitucional que tienen relación con las finanzas públicas. Se describen estas regulaciones jurídico financieras dentro de una Constitución también globalmente como 'Constitución Financiera'. ${ }^{24}$

Y manifiesta además que

la misión fundamental del Derecho constitucional, es la de encauzar el ejercicio del poder por el Derecho y asegurar las libertades públicas de los ciudadanos contra el ejercicio incontrolado del poder, no se extiende menos al terreno de la Hacienda que a cualquier otro ámbito de la actividad estatal [...] por eso hay que procurar que los principios constitucionales sean totalmente eficaces también en el campo de las finanzas públicas. ${ }^{25}$

Aunque tal definición es un tanto escueta, lo relevante de ambos criterios de Vogel está en el alcance que tiene el Derecho constitucional financiero en lo relativo a la eficacia que los principios constitucionales financieros han de tener en la práctica; al respecto, Yebra Martul-Ortega afirma que "la función del Derecho constitucional financiero va a consistir en hacer realidad esa igualdad jurídico-constitucional entre los distintos sujetos que intervienen en la actividad financiera"; ${ }^{26}$ que desde el constitucionalismo contemporáneo se apreciaría como ponderación entre los derechos y deberes que se incardinan en la obligación de contribuir.

\section{IMPORTANCIA DEL DERECHO CONSTITUCIONAL FINANCIERO}

Considerando que el principal objeto de estudio del Derecho constitucional financiero es el instituto jurídico del "deber de contribución al gasto público", es evidente que la importancia de esta rama jurídica gira en torno al referido deber y, por tanto, además en torno a los derechos del ciudadano obligado por aquel.

En ese sentido, es necesario comenzar señalando que el deber de contribución al gasto público se cumple a través del pago de los tributos establecidos en la ley, sin

24. KlausVogel, "Grundzüge des Finanzrechts des Grundgesetzes", en Der offene Finanz- und Steuerstaat (Heidelberg: C. F. Müller, 1991), 138.

25. Klaus Vogel, "La Hacienda pública y el Derecho constitucional”, Revista Hacienda Pública Española, No. 69 (1979): 16.

26. Perfecto Yebra Martul-Ortega, Constitución Financiera 25 años, 33. 
embargo, está asociado a un conjunto de preceptos que no son exclusivamente tributarios, sino financieros, ello debido a que su naturaleza es pecuniaria; mas se configura en calidad de vínculo jurídico impositivo que se debe en razón de un conjunto de principios constitucionales que ordenan el sistema tributario tales como capacidad contributiva, igualdad, generalidad, no confiscatoriedad, entre otros; del cumplimento de las obligaciones específicas de tributar por parte de los obligados, el Estado obtiene ingresos que están destinados a la satisfacción de necesidades comunes a través del gasto público, cuyas erogaciones deberán respetar principios generales como el de equidad y solidaridad; para lo cual habrá que remitirse necesariamente a la institución del presupuesto y sus principios especiales; sin olvidar que los ingresos tributarios están directamente relacionados con la fe crediticia del Estado y que para contraer deuda pública habrá de cumplirse a su vez con otros principios contemplados en diversas normas de la Constitución, que son parte de la denominada Constitución financiera.

\section{MODELOS ESTATALES Y CONSTITUCIÓN FINANCIERA}

Para comprender la importancia que las formas o modelos estatales tienen en la dinámica ingreso-gasto a través del deber de contribución al gasto público y los principios que le conciernen, es indispensable ahondar en la actividad del Estado ${ }^{27}$ desde una visión específica, es decir la financiera pública. La descripción que a continuación

27. El concepto "Estado" ha variado en sus definiciones conforme los hechos de la historia han permitido la ruptura de aquellos paradigmas que parecían inmutables en el tiempo, desde los grandes imperios como el Romano hasta los antiguos Estados monárquicos donde la expresión "el Estado soy Yo" y la confusión de los patrimonios del Estado y el monarca sufrieron una ruptura de paradigma de efecto mundial con los hechos acaecidos en la Revolución francesa en 1789, dando paso a un nuevo modelo estatal "liberal" con la conocida división tripartita del Estado magníficamente descrita por su precursor Charles Louis de Secondat, barón Montesquieu, en su obra El espíritu de las leyes en 1748, haciendo alusión a las tres funciones del Estado, conocidas como ejecutiva, legislativa y judicial. El mundo ha visto nacer y acaecer estados "sociales" puros, tales como la Unión de Repúblicas Socialistas Soviéticas, URSS, cuya separación incidió en el resurgimiento de los Estados 'neoclásicos' también llamados "neoliberales"; sin embargo, crisis económicas y conflictos bélicos, entre otros factores, han logrado desestabilizar nuevamente estas formas estatales, aunque prevalecen en grandes sistemas jurídicos como el anglosajón. Al mismo tiempo, en Estados más pequeños y vulnerables a las crisis, se revitalizan los "Estados sociales" con el importante agregado de "Derecho"; modelos que afrontan una nueva crisis, aparentemente producto de un positivismo extremo que subsume tanto a los poderes públicos como a los ciudadanos al "Derecho" y por ende al 'principio de legalidad' y no a la manifestación soberana del pueblo. Ello ha dado lugar al nacimiento un nuevo modelo de Estado conocido como el "Constitucional" donde predominan los "derechos" sobre el "Derecho" en sí mismo, modelo que ha llegado inclusive a mutar en extremos como el Estado Constitucional de derechos y justicia como es el caso ecuatoriano, conocido coloquialmente como el Estado del "socialismo del siglo XXI". 
se presenta hará énfasis en su rol en la satisfacción de las necesidades comunes a través del gasto público.

Previamente se habló de la Constitución financiera y los derechos, deberes y garantías que conciernen tanto a los poderes públicos como a los ciudadanos que de diversa forma participan en la actividad financiera del Estado; es precisamente en el marco de los derechos donde intrínsecamente se determinan e identifican las necesidades que ha de satisfacer el gasto público; Nora Lifschitz, contrastando su criterio con de autores como Félix Lon y Augusto Morelos, sostiene que "la Constitución es el depósito de aspiraciones esenciales de la comunidad [...] El proyecto social que incluye la Constitución nos imprime el sentido del modelo económico y de desarrollo que debe seguirse, conforme a él y a su dirección se elaboran los presupuestos. Los sistemas económicos y financieros surgen del orden constitucional" ${ }^{28}$ De tal forma que la Constitución es el eje fundamental del cual parte la actividad financiera del Estado.

No es particularmente fácil definir apropiadamente el término "necesidad" más aún dentro del orden de las finanzas públicas. Desde el precepto semántico gramatical podría definirse la necesidad como un componente básico cuya ausencia pone en riesgo la subsistencia y existencia de determinado ente u organismo, cualquiera sea su naturaleza (humana, social, individual, colectiva, política, gubernamental, etc.). En ese sentido, cada ente u organismo ha de completar sus componentes básicos para garantizar su propia subsistencia, por lo que desarrolla un sentido de pertenencia para con dichos componentes y por ende jerarquiza y clasifica sus necesidades con el objeto de satisfacer primero aquellas que le son de mayor importancia y urgencia.

Autores suramericanos como García Belsunse, ${ }^{29}$ Villegas, ${ }^{30}$ De la Garza,${ }^{31}$ Plazas Vega ${ }^{32}{ }^{2}$ Lifschitz ${ }^{33}$ y el tratadista ecuatoriano Riofrío Villagómez ${ }^{34}$ sostienen en sus diversas obras que el Estado es el depositario de las necesidades comunes y que esta

28. Nora Lifschitz, "La evolución del pensamiento jurídico financiero en América Latina", en Del Derecho de la Hacienda Pública al Derecho Tributario. Estudios en honor a Andrea Amatucci, vol. III (Bogotá: Temis, 2011), 51. Los autores remitidos por la autora son mexicanos y su obra ha sido recibida con entusiasmo en América del Sur, de ahí que se tome la cita tanto de la autora Nora Lifchitz que permite incorporar los criterios de Félix Lon y Augusto Morelos.

29. Horacio García Belsunce, "La ciencia de las Finanzas Públicas y la Actividad Financiera del Estado", en Tratado de Tributación, t. I, Derecho Tributario, vol. 1 (Buenos Aires: Astrea, 2003), 1-24.

30. Ver especialmente H. B. Villegas, Curso de finanzas, derecho financiero y tributario, 9a. ed., 2a. reimp. (Buenos Aires: Astrea, 2009), 1-78.

31. Sergio Francisco de la Garza, Derecho financiero mexicano (México: Porrúa, 2001), 1 y s.

32. M. Plazas Vega, Derecho de la Hacienda pública y Derecho tributario. Derecho de la Hacienda Pública, t. I, 2a. ed. (Bogotá: Temis, 2006), 320-5.

33. Lifschitz, "La evolución del pensamiento jurídico financiero en América Latina", 51 y s.

34. Eduardo Riofrío Villagómez, Tratado de finanzas públicas (Quito: Casa de la Cultura Ecuatoriana, 1962); y, Manual de Ciencia de las Haciendas (Quito: Imprenta del Ministerio del Tesoro, 1957). 
responsabilidad le faculta a través de los representantes políticos para determinar las necesidades que deben satisfacerse, la responsabilidad de los estados de la región crece aceleradamente a medida en que estos reforman sus Constituciones y asumen más roles y se autoimpone más obligaciones vinculadas a tales necesidades; en ese sentido, el crecimiento del gasto público incide significativamente en el incremento de obligaciones exigibles a los ciudadanos a fin de obtener recursos suficientes dentro de parámetros de justicia financiera.

Tal como sostiene Amatucci, la Constitución, al asumir la concepción de la actividad financiera, persigue esencialmente dos fines:

de un lado, impone la realización de la justicia financiera a través de la redistribución de las rentas, realizada a través de la progresividad del sistema tributario y una particular estructuración del gasto público, por otro lado permite que la actividad financiera constituya un instrumento de estabilidad del sistema económico en el tiempo, además que supone un adecuado desarrollo de la renta nacional. ${ }^{35}$

Es así que para la consecución de dichos fines se requiere dirección unitaria en la regulación de la actividad financiera del Estado, lo cual lleva implícita la configuración de un deber de contribución por parte del ciudadano y un poder conferido al Estado para exigir obligaciones puntuales.

Para comprender la importancia de esta rama jurídica merece la pena llevar a cabo un ejercicio comparativo entre constituciones de estados con modelos diferentes; en ese sentido, por la proximidad e influencia, se ha seleccionado como comparable al Estado español.

La configuración de un modelo estatal con su predefinido "modelo económico" lleva implícita una política fiscal; en ese sentido, el deber de contribución al gasto público ha de ser analizado en cada Estado en contexto a los principios y forma de organización que lo implementa, marcando la diferencia entre el análisis del "deber de contribuir al gasto público en la medida de la capacidad económica" de España, y "el deber de cooperar con el Estado en la seguridad social y pagar los tributos establecidos en la ley" de Ecuador.

La diferencia entre estas obligaciones es notoria no solo desde la construcción semántica del deber. Es claro que cada versión responde a un modelo estatal particular: mientras que el primero constitucionaliza la capacidad económica como principio informador del sistema tributario de un Estado socialdemócrata de Derecho que impone

35. Andrea Amatucci, Aspectos constitucionales de la actividad financiera (Bogotá: Instituto Colombiano de Derecho Tributario, 2002), 60 . 
límites a la contribución de los particulares al gasto público; por su parte el modelo ecuatoriano constitucionaliza la suficiencia recaudatoria en calidad de principio rector del régimen tributario de un Estado constitucional de derechos y de justicia donde las necesidades por ser satisfechas por el Estado son tantas y tan grandes que los recursos han de ser siempre insuficientes.

Con lo expuesto durante todo el capítulo queda claro que la adopción de determinado modelo estatal y su consecuente sistema económico lleva implícito la configuración de un conjunto de principios constitucionales financieros coherentes con un plan político de administración estatal.

Si bien al momento Ecuador y España mantienen modelos constitucionales teóricamente diferentes, en cuanto a la Constitución financiera durante décadas ha sido evidente una clara influencia del sistema español en el sistema ecuatoriano -particularmente en lo relativo a formas de imposición-; el régimen tributario ecuatoriano con sus particularidades ha constitucionalizado principios financieros en contextos similares, la progresividad es la nota común; las diferencias en cuanto a capacidad económica y suficiencia recaudatoria se deben a la planificación financiera y los objetivos de la política fiscal de cada Estado; en cualquier caso, en ambos sistemas jurídicos tanto en la parte dogmática de la Constitución como en su contenido material permiten referirse concretamente a una Constitución financiera puesto que una y otra contienen los principios, preceptos y contenidos mínimos que la doctrina considera forman parte de aquella.

Para Ruiz Almendral es evidente que la fórmula del Estado social tiene importantes consecuencias para toda la configuración de la Hacienda Pública en sus dos vertientes: la del ingreso y del gasto. Como consecuencia de la creciente intervención del Estado en las diferentes áreas de la vida social, el gasto público experimenta un considerable incremento. De ahí la necesidad de una fuente de financiación estable y fluida, que será proporcionada en gran parte por un sistema impositivo adecuadamente estructurado. ${ }^{36}$ Afirma además, que dentro de las exigencias del Estado social se encuentra aquella por la que el gasto público ha de ser repartido de forma equitativa, satisfaciendo con ellos las prestaciones sociales conforme lo previsto en la Constitución.

En ese sentido Rodríguez Bereijo sostiene que "en el Estado social y democrático de Derecho resulta cada vez más claro que la función de los tributos no es únicamente la de financiar los servicios públicos o del aparato estatal, sino también la distribuir la riqueza en el ámbito de la comunidad, ello implica que entre los impuestos y los

36. Violeta Ruiz Almendral, "Impuestos y Estado social”, en Juan Zornoza Pérez, coord., Finanzas públicas y Constitución (Quito: Tribunal Constitucional del Ecuador / Universidad Carlos III / Comisión Europea / Corporación Editora Nacional, 2004), 17. 
gastos públicos ha de existir una íntima conexión"; 37 los fines del Estado social, y más aún los del Estado constitucional, requieren de financiación. Al ser gastos ordinarios, requieren de ingresos ordinarios; por ende, el crecimiento de la economía del Estado refleja entonces el crecimiento de la economía de los particulares, a quienes se les obliga en forma general a contribuir al gasto en función de su capacidad contributiva.

En doctrina contemporánea se afirma que el Estado social precisa un sistema tributario para garantizar una fuente de financiamiento sostenida y estable; ${ }^{38}$ el deber de contribución al gasto público en ese esquema es precisamente la institución financiera que permite al Estado exigir la colaboración de los ciudadanos al cumplimiento de sus fines.

Cierro esta reflexión rescatando algunas ideas centrales, sin perjuicio de las conclusiones al finalizar la obra; la primera en relación a la concepción del Derecho constitucional financiero como línea de investigación, argumentando que no se trata de una rama del Derecho financiero, sino de aquella parte de este, que responde a un conjunto de principios cuyo origen está en la norma constitucional puesto que se refiere a deberes y derechos "fundamentales".

En cuanto al modelo de Estado, he de ratificar que el Estado constitucional es una forma, podría decirse, avanzada del Estado social de Derecho, cuya fortaleza se encuentra en la aplicación directa de la Constitución y por ende de los derechos y garantías en ella previstos; en ese sentido, el deber de contribución al gasto público ha de materializarse en aplicación estricta de los mismos para garantizar contribuciones justas; sobre este último punto ha de versar el tercer capítulo de esta obra.

Así la democracia representativa ${ }^{39}$ constituye el primer fundamento de orden jurídico/político del Derecho constitucional financiero; por lo tanto, se puede afirmar con certeza que existe el derecho subjetivo público de los ciudadanos de participar democráticamente en la aprobación de la ley tributaria y sus modificaciones; pues el deber de contribución al gasto público, además de límites concretos a los poderes públicos, lleva implícito un derecho civil de la sociedad en conjunto y cada uno de sus

37. Álvaro Rodríguez Bereijo, "El sistema tributario en la constitución. (Los límites del poder tributario en la jurisprudencia del Tribunal Constitucional)", Revista Española de Derecho Constitucional, No. 36 (1992): 17.

38. En ese sentido Ruiz Almendral V., "Impuestos y Estado Social”, 20.

39. Para una comprensión integral de este principio se recomienda revisar José Vicente Troya Jaramillo, "El Destino de las Contribuciones al Gasto Público. No taxation without representation vs. spending power", Revista Juridica de la Universidad Católica de Guayaquil (2014). Versión digital, también publicado en Temas de Derecho Tributario en homenaje al profesor Alfredo Benitez Rivas (Santa Cruz de la Sierra: Universidad Privada de Santa Cruz de la Sierra, 2010), 271-96. De acuerdo con Vogel, seguramente fue una casualidad que el principio de democracia representativa naciera de un postulado de Derecho constitucional financiero; no es difícil imaginarse que un objetivo de otro tipo podría haber ocasionado igualmente la exigencia de representación y participación políticas. Klaus Vogel, "La Hacienda pública y el Derecho constitucional”, 16. 
miembros de participar en las políticas del Estado; particularmente en la política fiscal a través de los procesos legislativos de formación y modificación de la ley tributaria, pues a través del cumplimiento efectivo del referido deber y las obligaciones específicas es que se obtienen finalmente recursos que se redistribuyen en la satisfacción de necesidades públicas.

\section{CONSIDERACIONES FINALES. HACIA UN RENOVADO DERECHO CONSTITUCIONAL FINANCIERO}

El Estado en su configuración actual ha crecido sustancialmente. Las necesidades financieras crecen significativamente frente a la disposición de recursos. El incremento de la población y el crecimiento del aparato estatal han vuelto insuficientes los recursos patrimoniales, haciendo de los recursos tributarios la principal fuente de ingresos públicos $\mathrm{y}$, consecuentemente, instrumentos eficientes de política pública.

La dinámica de la relación ingresos-gastos es objeto de conocimiento del Derecho financiero, cuya principal fuente, es la Constitución; en ella se configura el deber de contribución al gasto público y se establecen tanto los límites materiales al poder tributario del Estado, como los derechos y garantías de los ciudadanos contribuyentes.

En líneas generales deseo retomar la importancia del Derecho constitucional financiero en el sentido de que "la constitucionalización del deber de contribuir significó, desde luego, una mutación cualitativa en el proceso de su configuración jurídica, sobre todo a partir de la integración de sus elementos principales en un texto de vocación normativa, jurisdiccionalmente protegido"; ${ }^{40}$ haciendo del contenido de la Constitución financiera el más técnico y, en consecuencia, uno de los más complejos a instancias hermenéuticas.

Frente a las dificultades interpretativas de la Constitución financiera, el Derecho constitucional ha quedado en deuda epistemológica; mientras que los voluminosos manuales y tratados sobre la materia financiera responden o bien a una producción desde la ciencia de las finanzas públicas, o bien a estudios desde la visión autónoma de del Derecho financiero, y más aún del Derecho tributario, la materia constitucional aborda la temática del deber de contribución al gasto público en forma breve o introductoria, siendo, aunque destacados, pocos los artículos y documentos en la materia.

40. Francisco Escribano, “Actual configuración del Derecho financiero y tributario: Rol de la jurisprudencia constitucional y del Tribunal de Justicia de las Comunidades Europeas", en Jorge Bravo Cucci, Daniel Yacolca Estares y César Gamba Valega, dir., Introducción al Derecho financiero y tributario (Lima: AIDET-Jurista Editores E.I.R.L., 2010), 30. 
La tendencia contemporánea ha sido la de estudiar los principios constitucionales financieros en forma segmentada. La sistematización de contenidos se evidencia claramente en relación a principios conexos como igualdad, progresividad y capacidad económica, separándose del estudio de otros principios como el de equidad en el gasto público y proporcionalidad; por otro lado, los juristas inmersos en el Derecho constitucional, tal vez por recelo a la bien consabida especialidad, han dejado este espacio académico a los denominados especialistas ${ }^{41}$ en Derecho financiero y tributario, lo que deja un campo jurídico de trascendental importancia sustancialmente desatendido.

Personalmente entiendo el recelo que los investigadores en el área del Derecho constitucional puedan tener frente a la Constitución financiera, pues el objeto de estudio no se circunscribe únicamente al deber constitucional y a los principios que lo informan; se trata de una norma de compleja naturaleza jurídica, que se ha demostrado se relaciona con multiplicidad de derechos subjetivos, a los cuales me he venido refiriendo a lo largo de este escrito; derechos que nacen del contenido material de los principios y que se encuentran limitados por diversas reglas y técnicas fiscales de naturaleza económica.

En razón de lo expuesto, considero que es labor del jurista tributario con su conocimiento material y técnico del sistema tributario realizar los esfuerzos investigativos que sean necesarios para construir, desde la especialidad -a la que no me opongo-, investigaciones en esta área particular del Derecho financiero denominada Derecho constitucional financiero, sin intentar desagregarla o separarla del Derecho financiero en sí misma, pues no se aspira, al menos en este estudio, conferirle autonomía científica, pues, más allá de la especificidad de su contenido y de la bien consabida autonomía del Derecho tributario, parte de su contenido es esencialmente constitucional; y lo que se pretende es, precisamente, fomentar los estudios en esa línea de trabajo interdisciplinaria.

Ante los argumentos esgrimidos, en el presente trabajo ha pretendido, a partir del estudio del deber de contribución al gasto público, revitalizar y potenciar la investigación en el ámbito del Derecho constitucional financiero, cuya misión, de acuerdo con Vogel -a quien sigo en sus principales postulados-, es "encauzar el ejercicio del poder

41. Vogel, "La Hacienda pública y el Derecho constitucional”, 16. La ciencia del Derecho político, cuyo origen se encuentra en el modo aristotélico de pensar, no ha dedicado atención alguna a esta realidad durante mucho tiempo. También el profesor de Derecho constitucional evita, total o parcialmente, el estudio de la Constitución financiera dejándoselo a los especialistas. Con ello, no solo se está prescindiendo de una importante parte de la realidad constitucional sino que -y esto lo más lamentable-, al dejar el derecho financiero en manos de aquellos especialistas, cabe el peligro de que no se desarrolle al unísono con la Constitución en su conjunto, sino como algo separado de ella, incluso contrario a la misma: como una Constitución especial o incluso como una contraconstitución apócrifa. El autor afirma que hay que recordar a los profesores de Derecho constitucional que su responsabilidad respecto al Derecho financiero constitucional no desaparece con su silencio. 
por el Derecho y asegurar las libertades públicas de los ciudadanos contra el ejercicio incontrolado del poder", pues este, tal como nos dice el autor, "no se extiende menos al terreno de la Hacienda Pública que a cualquier otro ámbito de la actividad estatal"; 42 por eso hay que procurar que los principios constitucionales sean totalmente eficaces también en el campo de las finanzas públicas, lo cual conculca directamente a la protección y garantía de los derechos ciudadanos contribuyentes.

Concuerdo con Mortati cuando afirma que "la mención de los deberes necesariamente conexos con la posición del ciudadano no tienen razón de ser si no se hace con la finalidad de proceder a una especificación de las modalidades de su cumplimiento"; 43 estas disposiciones constitucionales contemporáneamente no vienen en forma exclusiva a configurar un deber ciudadano, limitado por un conjunto de principios; se trata hoy en día de un deber incurso en una gama de derechos subjetivos, que derivan precisamente de la concreción material de dichos principios en derechos cuya mención en el texto constitucional no es indispensable para garantizar su cumplimiento efectivo, pues se entiende que forman parte del vínculo jurídico impositivo.

Conviene destacar sin embargo que históricamente la aplicación de los principios que informan el deber de contribución al gasto público ha requerido en algunos casos, para alcanzar practicabilidad, la constitucionalización expresa de estos en la norma fundamental, tal es el caso de la Constitución de España.

En otros casos la no alusión textual a determinados principios en el texto constitucional -como es la Ley Fundamental de Bonn, en Alemania- no ha sido un impedimento para desarrollar en vía jurisprudencial el contenido material, alcance y parámetros de aplicación de aquellos, y de ello es una muestra el reconocimiento del derecho fundamental a contribuir en la medida de la capacidad contributiva que el Tribunal Constitucional Alemán ha conferido ya cierto desarrollo.

En ambos casos, el rol de la jurisprudencia ha sido de absoluta relevancia para comprender lo que se ha de entender por justicia en los términos más amplios que el Derecho pueda concretar a la materia tributaria.

Vogel, a través de algunos ejemplos, ${ }^{44}$ destaca la importancia de introducir los principios fundamentales de la Constitución en el Derecho financiero para conformar esta parcela jurídica. "En qué medida vaya a lograrse dependerá también del grado de coercibilidad que la propia Constitución establezca para sí misma"; pues "cuanto menos formalista sea una Constitución, seguramente será más flexible la legislación

42. Ibíd., 16 .

43. Constantino Mortati, Istituzioni di Dirito Pubblico (Padova: 1958), 746.

44. Ver Vogel, "La Hacienda pública y el Derecho Constitucional", 16-20. 
ordinaria, pudiéndose así adaptar con mayor vigor a las necesidades del momento (esto es prácticamente, a su mayoría)". ${ }^{45}$

Tal como había afirmado, se advierte peligrosamente en Ecuador una propensión a los fines recaudatorios, producto precisamente de esa ductilidad del texto constitucional que, por su configuración, deriva en una interpretación económica de la obligación de pagar tributos, sin configurar límites concretos.

La proliferación de leyes fiscales, nuevos impuestos y ajustes a los tributos vigentes es a lo que he venido refiriéndome como nueva condición de súbdito fiscal, y ello sorprendentemente dentro de un marco constitucional que, siendo garantista, no ha contemplado a los principales principios de justicia tributaria en la configuración de su régimen tributario, y que tampoco ha recocido formalmente un catálogo de derechos del contribuyente.

Por ende, siguiendo el pensamiento de Vogel, expreso la necesidad de reconocer los derechos y garantías de los obligados tributarios; ello, aunque difícil, puede obtenerse a partir de una interpretación finalista a partir del propio texto constitucional ecuatoriano, si lo ponemos en contexto con los fines de la política pública; para ello se ha requerido una revisión integral de la doctrina internacional y particularmente el respaldo de la jurisprudencia española, que ha sabido aportar a la construcción de un sistema tributario justo que, a pesar de no ser perfecto, ha dado pasos importantes en el reconocimiento de derechos y garantías de los contribuyentes, por lo que se espera, al transmitir sus experiencias, que se pueda aportar al desarrollo del régimen tributario considerando errores y aciertos de la visión comparada.

Tal como Escribano afirmó, es imposible explicar de forma coherente los cimientos fundamentales del Derecho financiero a espaldas de las decisiones jurisprudenciales, la integración del análisis constitucional de los principios que informan el deber de contribución al gasto público supuso pasar de la dogmática a la practicabilidad de los principios, y ese nivel de desarrollo se aspira alcanzar en el nuevo constitucionalismo en Ecuador.

Es así que en la configuración del deber de contribución al gasto público, se identifican -lo que puede denominarse-momentos; el primero en la elaboración misma de la norma constitucional que determina los principios materiales, bajo los cuales ha de cumplirse el referido deber; un segundo momento en el desarrollo normativo, donde el legislador cumple con el mandato de buscar riqueza y establecer gravámenes allí donde la encuentre; un tercer momento en el que el ciudadano contribuyente es efec-

45. Ibíd., 21. No siendo competente ni los jueces ni la administración para un examen material de la constitucionalidad de las leyes. 
tivamente conminado al pago de los diversos tributos; y un cuarto momento en el que el juez constitucional deberá conocer cuestiones de inconstitucionalidad y resolver acciones interpuestas ante posibles vulneraciones de sus derechos.

De acuerdo con las circunstancias históricas y políticas de cada Estado, en el primer momento el constituyente configura en la norma fundamental el deber de contribución al gasto público y determina el conjunto de principios que lo informan; ahora bien, en unos casos, más allá de diversos problemas interpretativos - de los cuales no está exenta ninguna Constitución-, algunas fórmulas constitucionales estructuran en forma más concreta y precisa el referido deber.

Ese es el caso de las Constituciones de España e Italia que establecen que la contribución al gasto público ha de ser en la medida de la capacidad contributiva; en otros casos, la formulación constitucional resulta no solo atípica sino además carente de concreción en cuanto al tema de los principios constitucionales y los límites de la contribución, este tipo de configuración es la que -a mi juicio- contiene la Constitución de Ecuador, que, además de omitir en el texto constitucional principios tradicionales de la imposición, constitucionaliza el deber de pagar los tributos establecidos en la ley, sin vincularlo directamente a un sistema tributario justo, como sí lo hacen otras Constituciones.

En un segundo momento, el desarrollo normativo que compete al legislador ha de aplicar los principios constitucionales en las leyes tributarias; por la regla de la generalidad todos tienen que pagar tributos, pero en cumplimiento de los principios de justicia, sobre todo los de capacidad contributiva e igualdad, pagarán quienes tengan aptitud para contribuir, y solo dentro de una medida concreta.

Ahora bien, ante el legislador todos los ciudadanos son iguales al momento de crear tributos, pero, como nos dice Ferreiro Lapatza, "la igualdad exige un trato igual a los iguales y desigual a los desiguales". Por tanto, "para la aplicación efectiva de estos principios es necesario determinar, primero, quién tiene y quién no tiene capacidad contributiva. Determinar lo que la doctrina ha llamado capacidad contributiva absoluta", establecido quiénes pueden y tienen que tributar, "es necesario fijar en qué medida tiene que tributar cada uno de ellos, de acuerdo con su capacidad contributiva relativa. De acuerdo con la medida de su capacidad en 'relación' comparándola con la 'capacidad de los demás" ". ${ }^{46}$

46. Ver José Juan Ferreiro Lapatza, Instituciones de Derecho financiero (Madrid: Marcial Pons, 2010), 193. En este punto vemos cómo el autor retoma la diferenciación que la doctrina italiana desarrolló sobre la capacidad contributiva absoluta y relativa. El principal aporte en este sentido es el de E. Giardina, Le basi teorche del principio della capacitá contributiva (Milano: Giuffrè, 1961), 52-3 y 55. 
Si bien, efectivamente debería diferenciarse entre la capacidad contributiva absoluta y relativa, la doctrina contemporánea ha sido -como ya hemos visto- bastante critica de estos esfuerzos doctrinarios; sin embargo, no puede olvidarse que es por mandato constitucional que el legislador debe buscar riqueza y crear tributos cuando la encuentre, pero ha de hacerlo dentro de unos límites muy concretos; por ello se requiere de una técnica legislativa especial, en materia tributaria.

Para ello, Ferreiro Lapatza afirma que el legislador:

obedeciendo a los textos constitucionales, procede generalmente de la siguiente forma: aísla ciertos hechos que, a su juicio, revelan en la generalidad, en la normalidad de los casos en que se realizan, capacidad económica; estos hechos demuestran indicios de capacidad contributiva, que a juicio del autor pueden ser directos o indirectos; yo considero que entre los primeros estaría la percepción de rentas o posesión de patrimonio, y en los segundos se encontraran hechos económicos tales como actividades de gasto o consumo. Sostiene además que a partir de estos indicios el legislador configura tales hechos como hechos imponibles, como hechos cuya realización determina el nacimiento de la obligación de contribuir. Quienes realizan tales hechos tienen capacidad contributiva absoluta, pueden y tienen que contribuir. ${ }^{47}$

Considerando que ciertas desigualdades son necesarias, para garantizar la justicia del sistema tributario, el legislador también es el responsable de establecer exenciones y de justificarlas además; en su libre opción política ha de considerar los fines fiscales y extrafiscales de los tributos, teniendo como bandera guía la igualdad y como fundamento la capacidad económica de los obligados.

En un tercer momento, cuando los contribuyentes que efectivamente realizaron hechos reveladores de su capacidad contributiva son por ley conminados al pago, se retoma el principio de igualdad en su significado material, de igualdad ya no ante la ley, sino la igualdad en la ley y por la ley ante la carga tributaria.

Uckmar sostiene que la igualdad ante la carga tributaria puede ser entendida en dos sentidos: a) en sentido jurídico "como paridad de posiciones, excluyendo los privilegios de clase, de raza y de religión, en manera que los contribuyentes se encuentren en iguales circunstancias y puestos ante un mismo régimen fiscal"; y b) en sentido económico como la obligación de contribuir a las cargas públicas en igual medida, entendido en términos de sacrificio y en relación a la capacidad contributiva de cada uno. ${ }^{48}$

47. Ver José Juan Ferreiro Lapatza, Instituciones de Derecho financiero, 193.

48. Víctor Uckmar, Principios comunes del Derecho constitucional tributario (Bogotá: Temis, 2002), 58. 
No puede olvidarse además que el Derecho comunitario ha tenido cierta efectividad, llámese incidencia en los ordenamientos tributarios de los Estados comunitarios, sin generar mayores incompatibilidades con el ejercicio del poder tributario.

De acuerdo con García Prats:

Aunque los resultados conseguidos por la acción comunitaria sobre el Derecho tributario pueda ser compatible con las exigencias internas, el derecho comunitario comporta novedades que al menos si modifican la construcción de los principios de justicia internos y su desarrollo, de modo que la importancia de la acción comunitaria reside, tal como dice el autor, en la incorporación de nuevos criterios interpretativos, justificativos y orientadores del ordenamiento. ${ }^{49}$

Es precisamente el Derecho comunitario una de las fuentes principales de conocimiento, de cuyo contenido se desprende la existencia de varios derechos de los contribuyentes obligados por el deber de contribuir para con el gasto público del Estado miembro; la seguridad jurídica, el principio de proporcionalidad, los principios de no discriminación y neutralidad; así como el preponderante rol de los Tribunales supranacionales en la protección de los derechos fundamentales reconocidos por la Comunidad, y la salvaguarda de los objetivos comunitarios, evidencian el nacimiento de nuevos y más amplios derechos de contribuyentes que, estando obligados para con un Estado, forman parte al mismo tiempo de una Comunidad con objetivos globales y mecanismos de protección abiertos.

Uno de los peligros que puede derivar del proceso de integración comunitaria es la aplicación obligatoria de principios económicos como el de neutralidad, pues la primacía del Derecho comunitario coadyuva a su consolidación; sin embargo, puede generar problemas derivados de la imposibilidad de articular los principios comunitarios al ámbito parcial de la exigencia del principio de no discriminación, lo cual puede producir quiebras entre los sistemas tributarios y los instrumentos de integración, y tal como García Prats advierte, provocar quiebras en la unidad y coherencia interna de los sistemas tributarios sobre los que inciden. ${ }^{50}$

49. Ver Francisco García Pratz, "Incidencia del Derecho Comunitario en la configuración jurídica del Derecho Financiero (I): La acción del Tribunal de Justicia de Luxemburgo", Revista de Derecho Financiero y Hacienda Pública, No. 259 (2001): 746.

50. Ibíd., 747-8. Una situación como esta fue resuelta por el Tribunal de Justicia de la Comunidad Europea y sentó un importante precedente con la sentencia de 17 de julio de 1997. Asunto C-28/95. Caso A. Leur-Bloem C. Inspectur der Belastingdient Ondernemingen Ámsterdam 2, sobre la interpretación de la Directiva 90/434/ C.E.E. sobre el tratamiento fiscal de fusiones. El Tribunal realizó una interpretación uniforme del derecho comunitario en un caso concreto, derivado no de la no aplicación inmediata, sino porque el legislador nacional había decidido, al adaptar el derecho nacional a las disposiciones de una Directiva, dispensar el mismo trato a la situaciones puramente internas y las que regla la Directiva, ajustando su legislación interna al Derecho comunitario para 
Cierro este apartado con una referencia a Vogel, quien sostiene que las Constituciones son obras del hombre y, ya solo por este hecho, puede que no sean perfectas: son los intentos de una nación por establecer un orden jurídico humanamente digno. ${ }^{51}$ El Derecho financiero se dedica al estudio e investigación de aquel conjunto de normas que regulan la actividad financiera del Estado, que es precisamente la actividad que le permite al ente estatal mantenerse vivo a sí mismo y establecer condiciones de vida digna para los ciudadanos que del el forman parte.

\section{CONCLUSIÓN}

En cuanto a los objetivos específicos propuestos para este artículo, en lo relativo a estudiar esta rama jurídica desde sus raíces para desentrañar su filiación a una rama determinada, debo concluir que el Derecho financiero público no puede ni debe ser declarado autónomo, los interminables debates para ratificar su autonomía no hacen más que profundizar divorcios incensarios entre ramas del derecho público que de hecho son complementarias y auxiliares; así, el escaso desarrollo del Derecho constitucional financiero ha sido perjudicial para el desarrollo de los derechos del contribuyente, pues de haber reconocido con mayor vehemencia la importancia de esta rama jurídica, el deber de contribución al gasto público habría tenido como contraparte la configuración jurídica de un derecho proporcional a contribuir en la medida de una capacidad económica que no vulnere derechos de los ciudadanos aportantes.

El Derecho constitucional financiero tiene la misión fundamental de delimitar conceptualmente no el ámbito de los principios del deber de contribución al gasto público, sino, más bien, de los límites del poder del Estado frente a la gran gama de derechos subjetivos que han quedado expuestos en estas líneas y a los cuales se ha pretendido dar una primera delimitación conceptual, pues, tal como se ha venido afirmando, el contribuyente está asistido de derechos y garantías de cuyo cumplimiento los efectos no son únicamente incidentes en el ciudadano aportante, sino también en toda la comunidad que se beneficia del gasto público y por ende de la contribución solidaria.

Finalmente, las innegables conexiones entre el sistema tributario y el sistema de redistribución del recurso público evidencian que la afectación de los derechos de

evitar situaciones discriminatorias en perjuicio de las no amparadas por el Derecho comunitario. Dejó en claro el Tribunal que existe un interés común manifiesto que se centra en la finalidad de evitar "la aparición de discriminaciones en contra de los propios intereses nacionales", o bien, "de eventuales distorsiones de la competencia" en contra de los mismos por lo que, en dicho caso, las disposiciones o conceptos internos pueden recibir una interpretación uniforme. Cfr., ibíd., 748-9.

51. Ver Vogel, "La Hacienda pública y el Derecho Constitucional”, 23. 
unos cuantos contribuyentes afecta significativamente al conglomerado social, pues atenta contra los principios fundamentales del Estado de Derecho, dado que la solidaridad no tiene alcance limitado a la redistribución, sino que deviene de la solidaridad también en la recaudación.

\section{BIBLIOGRAFÍA}

Amatucci, Andrea. Aspectos constitucionales de la actividad financiera. Bogotá: Instituto Colombiano de Derecho Tributario, 2002.

Arche-Domingo, Vicente. "Hacienda Pública y Administración Pública". Hacienda Pública Española, No. 26 (1974).

Asorey, Rubén, Andrea Amatucci y Mauricio Plazas Vega. La autonomía del Derecho de la Hacienda pública y el Derecho tributario. Bogotá: Universidad del Rosario, 2008.

De la Garza, Sergio Francisco. Derecho financiero mexicano. México: Porrúa, 2001.

De la Guerra, Eddy. El deber de contribución al gasto público y los principios que le rigen. Madrid: Universidad Complutense de Madrid, programa de Doctorado en Derecho, 2016.

Escribano, Francisco. "Actual configuración del Derecho financiero y tributario: Rol de la jurisprudencia constitucional y del Tribunal de Justicia de las Comunidades Europeas". En Jorge Bravo Cucci, Daniel Yacolca Estares y César Gamba Valega, dir., Introducción al Derecho financiero y tributario. Lima: AIDET-Jurista Editores E.I.R.L., 2010.

Ferrajoli, Luigi. Derechos y garantías. Madrid: Trotta, 1999.

---. Los fundamentos de los derechos fundamentales. Madrid: Trotta, 2009.

Ferreiro Lapatza, José Juan. Curso de Derecho financiero español, 14a. ed. Madrid: Marcial Pons, 1992.

---. Instituciones de Derecho financiero. Madrid: Marcial Pons, 2010.

García Belsunce, Horacio. "La ciencia de las finanzas públicas y la actividad financiera del Estado". En Tratado de tributación, t. I, Derecho Tributario, vol. 1. Buenos Aires: Astrea, 2003.

Giannini, Achile Donato. Instituciones de Derecho tributario. Traducción y estudio preliminar de Fernando Sainz de Bujanda. Madrid: Editorial de Derecho Financiero, 1957.

Giardina, E. Le basi teorche del principio della capacitá contributiva. Milano: Giuffrè, 1961.

Lifschitz, Nora. "La evolución del pensamiento jurídico financiero en América Latina". En Del Derecho de la Hacienda pública al Derecho tributario. Estudios en honor de Andrea Amatucci, vol. III. Bogotá: Temis, 2011.

Mortati, Constantino. Istituzioni di Diritoo Pubblico. Padova, 1958.

Myrbach-Rheinfeld, Frans von. Précis de Droit Financier. Leipzing: Verlag von Duncker \& Humblot, 1906. Versión francesa: Précis de Droit Financier. París: V. Giard \& E. Briere, 1910. 
Plazas Vega, Mauricio. Derecho de la Hacienda pública y Derecho tributario. Derecho de la Hacienda pública, t. I, 2a. ed. Bogotá: Temis, 2006.

Rodríguez Bereijo, Álvaro. "El sistema tributario en la constitución. (Los límites del poder tributario en la jurisprudencia del Tribunal Constitucional)". Revista Española de Derecho Constitucional, No. 36 (1992).

---. Introducción al estudio del Derecho financiero. Madrid: Instituto de Estudios Fiscales, 1976.

Ruiz Almendral, Violeta. "Impuestos y Estado social”. En Juan Zornoza Pérez, coord., Finanzas públicas y Constitución. Quito: Tribunal Constitucional del Ecuador / Universidad Carlos III / Comisión Europea / Corporación Editora Nacional, 2004.

Sainz de Bujanda, Fernando. Sistema de Derecho financiero, I, Introducción. Actividad financiera, ciencia financiera, y Derecho financiero, vol. I. Madrid: Universidad Complutense de Madrid, 1977.

Uckmar, Víctor. Principios comunes del Derecho constitucional tributario. Bogotá: Temis, 2002.

Villegas, H. B. Curso de finanzas, derecho financiero y tributario, 9a. ed., 2a. reimp. Buenos Aires: Astrea, 2009.

Vogel, Klaus. “Grundzüge des Finanzrechts des Grundgesetzes”. En Der offene Finanz- und Steuerstaat. Heidelberg: C. F. Müller, 1991.

---. “La Hacienda pública y el Derecho constitucional”. Revista Hacienda Pública Española, No. 69 (1979).

Zagrebelsky, Gustavo. El Derecho dúctil. Madrid: Trotta, 2005.

Fecha de recepción: 13 de enero de 2017.

Fecha de aprobación: 15 de julio de 2017. 